\title{
Limited influence of marine sediment lyophilization on prokaryotic community structure assessed via amplicon sequencing - An example from environmentally contrasted sediment layers in Toulon harbor (France)
}

\author{
Benjamin Misson ${ }^{\text {Corresp., } 1}$, Cédric Garnier ${ }^{1}$, Alexandre J Poulain ${ }^{2}$ \\ 1 Université de Toulon, Aix Marseille Univ., CNRS, IRD, MIO, Toulon, France \\ 2 Department of Biology, University of Ottawa, Ottawa, Ontario, Canada \\ Corresponding Author: Benjamin Misson \\ Email address: misson@univ-tln.fr
}

Sediment lyophilization is a common process that allows for long-term conservation and sharing of marine sediments for multiple downstream analyses. Although it is often used for geochemical studies, the effects of lyophilization on prokaryotic taxonomic diversity assessment remained to be assessed. Here, we tested the effect of lyophilization on microbial diversity assessment using three sediment layers corresponding to various sediment ages and chemical contamination levels sampled from a marine Mediterranean harbor. Duplicate DNA samples were extracted from wet frozen or lyophilized sediments, and $16 S$ rRNA gene amplicon sequence variants were analyzed. We detected changes in community structure over depth linked to both dominant and less abundant taxa whether sediments were lyophilized or not. Data from both wet frozen and lyophilized sediments led us to conclude that historical chemical contamination of the sediment of Toulon Bay did not appear to be the main environmental variable shaping prokaryotic community structure on the vertical dimension, but that sediment diagenesis was. We conclude that sediment lyophilization is compatible with marine biogeochemical and ecotoxicological studies but that caution should be used when discussing small variations among samples. 
1 Limited influence of marine sediment lyophilization on

2 prokaryotic community structure assessed via amplicon

3 sequencing - An example from environmentally contrasted

4 sediment layers in Toulon harbor (France)

5

6

7 Benjamin Misson ${ }^{1}$, Cédric Garnier ${ }^{1}$, and Alexandre J. Poulain ${ }^{2}$

8

9 ' Université de Toulon, Aix Marseille Univ., CNRS, IRD, MIO, Toulon, France.

$10{ }^{2}$ Biology Department, University of Ottawa, Ottawa, Canada

11

12 Corresponding Author:

13 Benjamin Misson ${ }^{1}$

14 Université de Toulon

15 Bâtiment R

16 CS 60584

1783041 Toulon cedex 9

18 Email address: misson@univ-tln.fr 


\section{Abstract}

22 Sediment lyophilization is a common process that allows for long-term conservation and sharing 23 of marine sediments for multiple downstream analyses. Although it is often used for geochemical 24 studies, the effects of lyophilization on prokaryotic taxonomic diversity assessment remained to 25 be assessed. Here, we tested the effect of lyophilization on microbial diversity assessment using 26 three sediment layers corresponding to various sediment ages and chemical contamination levels 27 sampled from a marine Mediterranean harbor. Duplicate DNA samples were extracted from wet 28 frozen or lyophilized sediments, and 16S rRNA gene amplicon sequence variants were analysed. 29 We detected changes in community structure over depth linked to both dominant and less 30 abundant taxa whether sediments were lyophilized or not. Data from both wet frozen and 31 lyophilized sediments led us to conclude that historical chemical contamination of the sediment 32 of Toulon Bay did not appear to be the main environmental variable shaping prokaryotic 33 community structure on the vertical dimension, but that sediment diagenesis was. We conclude 34 that sediment lyophilization is compatible with marine biogeochemical and ecotoxicological 35 studies but that caution should be used when discussing small variations among samples. 


\section{Introduction}

Linking chemical contamination to ecological effects through genomic approaches remains challenging. Multidisciplinary approaches are needed, but their application often requires that varying sample amounts and sometimes different conservations means be used. Marine sediment conservation for inorganic contamination evaluation often require freeze-drying (e.g. Tessier et al., 2011; Dang et al., 2015; Outridge et al., 2017). In order to couple microbial community structure analyses with geochemical investigations, the same samples need to be processed for different downstream analyses. One question that microbiologists interested in geochemical processes often face is whether sediment freeze-drying, typically required to determine metal burden per dry mass of sediment, is compatible with microbial studies. If yes such sample conservation could facilitate collaborative work performed by distant laboratories.

A previous study on freeze-dried soil and freshwater sediment samples (Miller et al., 1999) demonstrated the ability to use freeze-dried samples to extract and amplify microbial DNA, but no comparison with results obtained with wet samples was provided. More recently, Gianaroli et al., (2012) demonstrated by using microscopy that DNA integrity was not altered in freeze-dried eukaryotic cells when compared to fresh ones. With recent advances in high throughput sequencing and downstream bioinformatics analyses, we can question whether more subtle consequences on DNA structure or extraction could interfere with microbial diversity assessments because of sediment freeze-drying.

A recent study targeting soil samples, using 454 pyrosequencing and focusing on nucleic acids conservation, demonstrated that alpha- and beta-diversity were poorly affected by freezedrying (Weißbecker, Buscot \& Wubet, 2017). However, the taxa encountered were not reported. Given the very large microbial diversity in soil or sediment, it is reasonable to expect differential conservation of microbial DNA upon freeze-drying and/or recovery during DNA extraction based on cell wall properties or even DNA sequences (e.g., low vs. high GC).

Furthermore, marine coastal sediments are rich in salts and humic acids, potentially inhibiting PCR amplification (Kreader, 1996), and increasingly subject to anthropogenic contaminants, among which divalent metallic cations can negatively alter nucleic acids recovery during the extraction procedure (Stein et al., 2001). These chemicals are further concentrated during sediment freeze-drying, thus potentially challenging microbial community structure assessment. Validating the suitability of molecular tools on DNA extracted from freeze-dried sediments is still necessary (Bey et al., 2010).

This study aimed at comparing prokaryotic community diversity determined by MiSeq high throughput sequencing of 16S rRNA gene amplicon from DNA extracted from wet frozen or freeze-dried marine sediments. Our analysis focused on alpha and beta diversity metrics. We used highly contaminated sediments from the Toulon Harbour (NW Mediterranean Sea, France) which anthropogenic recent and historical chemical contamination was previously characterized 
75

76

77

78

79

80

81

82

83

84

85

86

87

88

89

90

91

92

93

94

95

96

97

98

99

100

101

102

103

104

105

106

107

108

(Misson et al., 2016). In addition to testing for the role of lyophilization on diversity assessment, we were interested in evaluating the relative contribution of this contamination and of naturally occurring processes such as diagenesis on prokaryotic diversity. To do so, we used 3 sediment layers spanning 150 years of sedimentation and capturing the main contamination event associated with the scuttling of the French fleet during World War II.

\section{Materials \& Methods}

\section{Sediment sampling and conditioning}

The sampling site is located in the heavily multi-contaminated Toulon Bay (France), at sampling station \#12, (43ㅇ' $\left.34.9^{\prime \prime} \mathrm{N}, 5^{\circ} 55^{\prime} 41.1^{\prime \prime} \mathrm{E}\right)$ previously intensively studied by Dang et al. (2014). A $50 \mathrm{~cm}$-long and $10 \mathrm{~cm}$-diameter sediment core was sampled in a PlexiGlass ${ }^{\circledR}$ tube with the help of divers in September 2015. Additional details concerning the chemical contamination in this area of Toulon bay can also be retrieved from other studies (Tessier et al., 2011; Pougnet et al., 2014; Misson et al., 2016; Wafo et al., 2016). Sampling was performed with the authorization of the Laboratoire d'Analyse, de Surveillance et d'Expertise de la Marine (LASEM) Nationale de Toulon.

The core was sliced under nitrogen-enriched atmosphere using sectioning material previously sterilized with bleach and cleaned for trace metal sampling with trace metal grade nitric acid. The core was sectioned every $1 \mathrm{~cm}$ from depths 0 to $20 \mathrm{~cm}$ and subsequently every 2 $\mathrm{cm}$ from depths 20 to $46 \mathrm{~cm}$. Half of each sediment slice was immediately stored at $-20^{\circ} \mathrm{C}$ and freeze-dried for a period of 72 hours under a vacuum of $10^{-5}$ atm with a Pilot PCCPLS15 freeze dryer (Cryotec) and then homogenized. These lyophilized sediments were further used for $\mathrm{Hg}$ content determination as well as DNA extraction. The other half (subsequently called "frozen" sediments) was immediately rinsed with a sterile buffer (SB) composed of $10 \mathrm{mM}$ EDTA, 50 $\mathrm{mM}$ TrisHCl and $50 \mathrm{mM} \mathrm{Na}_{2} \mathrm{HPO}_{4}$ at $\mathrm{pH} 8$ to remove contaminants such as humic substances and divalent cations (Brazeau et al., 2013). After centrifugation at 8,000 $\mathrm{x} g$, the pellet was stored at $-20^{\circ} \mathrm{C}$ until DNA extraction.

\section{Hg analyses}

Total $\mathrm{Hg}$ in sediments was analyzed as previously described (Poulain et al. 2015). Specifically, total mercury was analyzed by thermal decomposition with gold trap amalgamation and cold vapour atomic absorption method (UOP Method 938-00, detection limit of $0.01 \mathrm{ng} \mathrm{Hg}$ and range up to $1000 \mathrm{ng} \mathrm{Hg}$ ) using a Nippon Instruments Corporation's Mercury SP-3D Analyser (CV-AAS). The instrument was calibrated with Mercury Reference Solution 1000 ppm 
109

110

111

112

113

114

115

116

117

118

119

120

121

122

123

124

125

126

127

128

129

130

131

132

133

134

135

136

137

138

139

140

141

142

143

$\pm 1 \%$ (Fisher CSM114-100) and MESS-3 (91 \pm 9 ng g-1, National Research Council of Canada)

was used as reference material. Blanks were performed as suggested by the manufacturer.

\section{DNA extraction}

To compare samples from different ages and contamination levels, three sediment slices were chosen: superficial sediments corresponding to recent deposits $(0-1 \mathrm{~cm},<5$ years according to settling rates in the bay; Tessier et al., 2011), mid-depth sediments corresponding to the historical contamination event (10-11 cm, see the results section, 75 years old) and deep sediments corresponding to an older period with a limited human impact on the site $(19-20 \mathrm{~cm}$, $\sim 150$ years old; figure 1).

For each sediment slice, two subsamples were taken from lyophilized material and two others from frozen material, leading to a total of 12 samples treated for molecular analyses. DNA was extracted from $250 \mathrm{mg}$ of freeze-dried or $250 \mathrm{mg}$ of frozen sediments. After weighting, freeze-dried sediments were rehydrated in $400 \mu \mathrm{L}$ of SB for $1 \mathrm{~h}$ at $4^{\circ} \mathrm{C}$. Then DNA extraction was performed concomitantly by two experimentalists using PowerSoil DNA Isolation Kit (MoBio) according to manufacturer's protocol. DNA concentration and purity were estimated using a NanoDrop ND 1000. DNA extracts were then stored at $-20^{\circ} \mathrm{C}$ until further use.

\section{Quantification of bacterial 16S rRNA gene copies}

To evaluate whether sediment lyophilization could have reduced the efficiency of DNA extraction, bacterial 16S rRNA gene copies were quantified using qPCR and primers BAC338f/515R (Borrel et al., 2012). Amplification reactions were performed in triplicate in a LightCycler 480 thermocycler (Qiagen) with GoTaq SybrGreen mastermix (Promega) in a final volume of $10 \mu \mathrm{l}$ containing $0.25 \mu \mathrm{M}$ of each primer and $2 \mu \mathrm{L}$ of 20 -fold diluted DNA extract to avoid PCR inhibition. Serial 10-fold dilutions of a linearized recombinant plasmid ranging from $10^{7}$ to $10^{2}$ copies were also amplified in triplicate to produce a standard curve used for determining $16 \mathrm{~S}$ rRNA gene copy number in the samples. According to the standard curve slope, the reaction yielded an efficiency of $97 \%$.

16S rRNA gene copy numbers were reported to the mass of frozen sediments used for extraction. In the case of lyophilized samples, the water content of the sediment (64\%) observed previously at the same site was used to calculate the equivalence between dry and wet weights (Tessier, 2011).

\section{Evaluation of prokaryotic community diversity}

Amplification of the V4-V5 region of 16S rRNA gene targeting bacteria and archaea was performed using primers 515F-Y/926R (Parada, Needham \& Fuhrman, 2016). Reaction mixtures contained 30 to $60 \mathrm{ng}$ of DNA, 2x GoTaq Long PCR Master Mix (Promega) and $0.4 \mu \mathrm{M}$ of each 
144 primer, in a final volume of $60 \mu \mathrm{L}$. The PCR program included an initial heating step of 2' at $14595^{\circ} \mathrm{C}$ followed by 25 cycles of $95^{\circ} \mathrm{C}$ for $30^{\prime \prime}, 50^{\circ} \mathrm{C}$ for $45^{\prime \prime}$ and $72^{\circ} \mathrm{C}$ for $45^{\prime \prime}$, and a final 146 extension of $10^{\prime}$ at $72^{\circ} \mathrm{C}$. PCR amplification efficiency and specificity was checked after 147 migration of $5 \mu \mathrm{L}$ of PCR products on a $1.5 \%$ agarose gel. Extraction blank performed with 148 MilliQ water as well as no-template PCR control did not provide any amplification products. 149 Amplicons were then purified, fused with Illumina barcodes and paired-end sequenced ( 2 × 250 150 bp) with the chemistry V2 and an Illumina MiSeq sequencer by the GeT-PLaGe platform 151 (Castanet-Tolosan, FRANCE).

152 MiSeq raw reads were analyzed with DADA2 (Callahan et al., 2016) in RStudio (R Core 153 Team, 2017). Sequences were trimmed according to average Q-scores, then filtered allowing no 154 N, no more than 2 expected errors whatever the read (i.e. forward or reverse) and a minimal Q155 score of 3. Taxonomic information was assigned to ASVs with the SILVA v.132 database 156 (Pruesse et al., 2007; Quast et al., 2013). Sequences classified as mitochondria or chloroplasts 157 were removed from the ASV table. Subsampling at the same sequencing depth for all sample did 158 not appear necessary for further alpha and beta diversity computation, because rarefaction curves 159 of each sample showed a plateau (see the results section). Sequencing reads were deposited in 160 the National Center for Biotechnology Information Sequence Read Archive (NCBI SRA) under 161 the accession number PRJNA599066. Rarefaction curves, alpha diversity calculations (including 162 estimates of rarefaction, Chao1, Shannon and Simpson's indexes), weighted UniFrac distances 163 and PCoA were calculated and constructed with RStudio using the phyloseq (McMurdie and 164 Holmes, 2013) and vegan (Oksanen et al., 2019) packages.

165 
167 Results

168 Historical contamination profile

169 Concentrations of $\mathrm{HgT}$ spanned 2 orders of magnitude, ranging from 0.37 to $15 \mathrm{ppm}$. The

170 vertical profile exhibited stable and low $\mathrm{HgT}$ concentrations $(0.4-1.1 \mathrm{ppm})$ at the bottom of the

171 core (from -46 to $-28 \mathrm{~cm}$ ), then a first increase to $3.3 \mathrm{ppm}$ was recorded (from -28 to $-19 \mathrm{~cm}$ )

172 before a second but sharper increase towards the maximal historical contamination (recorded at -

$17312 \mathrm{~cm})$. Concentrations subsequently decreased from ca. $12 \mathrm{~cm}$ to stabilize at $\sim 5 \mathrm{ppm}$ in the top $1748 \mathrm{~cm}$ (Fig. 1).

175

176

\section{Prokaryotic community abundance and diversity}

177

178

179

180

181

182

183

184

185

186

187

188

189

190

191

192

193

194

195

196

197

198

199

200

201

202

Bacterial 16S rRNA gene copy number was recorded as a proxy of prokaryotic abundance. Once normalized to sediment wet weight (or equivalent) used for extraction, values ranged from 0.93 to $6.42 \times 10^{8}$ copies. $\mathrm{g}^{-1}$ and from 0,73 to $6,71 \times 10^{8}$ copies. $\mathrm{g}^{-1}$ for frozen and lyophilized sediments, respectively. Whatever the sediment conditioning before extraction, a similar decreasing trend with depth was observed, especially between $0-1 \mathrm{~cm}$ and 10-11 cm (Fig. 2). In spite of this common trend, a higher variability was recorded for lyophilized sediment from $0-1$ $\mathrm{cm}$.

Sequencing the prokaryotic community yielded 2,396 ASVs from 108,216 sequences. Rarefaction curves demonstrated that a plateau was reached quickly for all samples (Fig. 3A-C). The observed richness per sample ranged between 141 and 722 ASVs. As observed for 16S rRNA gene copies, the observed richness at $0-1 \mathrm{~cm}$ after lyophilization appeared highly variable (Fig. 4A). However, it should be noted that the sample showing the lowest richness was not the one showing the lowest $16 \mathrm{~S}$ rRNA gene copy number. At $10-11 \mathrm{~cm}$, both observed richness values and variability appeared similar for frozen and lyophilized sediment (Fig. 4B). At 19-20 $\mathrm{cm}$, the variability among replicates was similar for both frozen and lyophilized sediment, but the observed richness appeared higher for lyophilized sediments. Other alpha diversity metrics, Shannon and reciprocal Simpson indexes, presented a higher variability for lyophilized than for frozen sediment at 0-1 cm, and also at 19-20 cm. We observed far lower values of Shannon and reciproqual Simpson indexes for one replicate at 19-20 cm (Fig. 4C). Finally, DNA extracted from frozen sediment led to a slight increasing trend with depth for all metrics, a trend that could not be observed from lyophilized material because of the higher variability observed.

ASVs were distributed among 49 phyla corresponding mainly to Bacteria. Indeed, after extraction from frozen sediment, the proportion of archaeal sequences ranged from 0.3 to 14.0 $\%$. Archaeal ASVs were more represented at $10-11 \mathrm{~cm}$ and $19-20 \mathrm{~cm}(9.4-14.0 \%)$ than in the surface layer $(0.3 \%)$. The same trend was observed for lyophilized sediments, Archaea being undetected or rare at $0-1 \mathrm{~cm}(0-0.3 \%)$, and more abundant in intermediate $(12.3-14.3 \%)$ and 
203 deep layers (13.5 - 17.4\%). Among the bacterial phyla encountered, Proteobacteria (especially 204 Delta- and Gammaproteobacteria), Chloroflexi (especially Dehalococcoidia) and Bacteroidetes 205 were dominant and accounted for 40.8 to $70.9 \%$ of the community recovered from frozen 206 sediment (figure 5). Strong vertical variations in community structure were recorded, mainly 207 between the surface layer, on the one hand, and intermediate and deep layers, on the other.

208 Gammaproteobacteria and Bacteroidetes were dominant groups in the surface layer (24.1 - 38.5 $209 \%$ and $12.7-13.2 \%$, respectively) but largely decreased in intermediate and deep layers ( 0.2 $210 \quad 10.8 \%$ and $1.5-2.6 \%$, respectively). We noted that Dehalococcoidia strongly increased in 211 intermediate and deep layers (16.6 - 18.9\% and $23.6-23.8 \%$, respectively) when compared to 212 the surface (from undetected to $0.3 \%$ ). This vertical structure shift appeared highly reproducible 213 between frozen and lyophilized sediment samples at all depths (Fig. 5A-C), although the 214 proportion of Gammaproteobacteria in one deep lyophilized sample appeared abnormally high 215 (12,1\%). In the same sample, Firmicutes reached $16.7 \%$ while they were not detected in the 216 other samples from the same depth.

217 Taking into account the whole community and not only dominant phyla or classes, 218 weighted UniFrac distance analysis performed at the ASV level largely confirmed both the 219 vertical trend, and the similarities observed between lyophilized and frozen sediments. As 220 demonstrated by Fig. 6, the large majority of community structure variation was recorded 221 between the surface layer and the other two samples, their separation being evident on the first 222 axis of the PCoA representing more than $90 \%$ of the variability whatever treatment before DNA 223 extraction was applied (Figure 6A and B). Some variability among replicates (at $0-1 \mathrm{~cm}$ for 224 frozen sediments and $19-20 \mathrm{~cm}$ for lyophilized ones) could be observed along the second axis, 225 representing 3.0 to $4.3 \%$ of the variability. When considering both treatments together (Figure 226 6C), the second axis allowed to discriminate intermediate $(10-11 \mathrm{~cm})$ and deep samples $(19-20$ $227 \mathrm{~cm}$ ) as well as support the influence of sediment treatment (fro vs. lyo). Although this 228 observation could suggest some phylogeny-related susceptibility to lyophilization, the small 229 representation of the biological variability on the second axis (3.4\%) tends to indicate that such 230 difference could be restricted to rare groups and only slightly alter our assessment of community 231 structure.

232

233

234

Peer) reviewing PDF | (2020:04:47389:1:1:NEW 26 Jan 2021) 


\section{Discussion}

236

237 In this study, we evaluated the influence of sediment freeze-drying on 16S rRNA gene amplicon 238 diversity analyses using three sediment layers collected from a sediment core.

239

240

241

242

243

244

245

246

247

248

249

250

251

252

253

254

255

256

257

258

259

260

261

262

263

264

265

266

267

268

269

270

271

The highest congruence between results obtained from frozen and lyophilized sediments was for beta diversity analyses. Indeed, at the ASV level, within layer differences observed for frozen or lyophilized materials appeared lower than when comparing frozen vs. lyophilized samples. Very few differences were observed for dominant groups although some replicate showed singular community structure for either frozen or lyophilized sediment. We did not observe an effect of DNA extraction or degradation leading to a qualitative bias, which is in agreement with the absence of an effect of lyophilization on DNA structure within cells (Gianaroli et al., 2012).

When considering alpha diversity, sediment lyophilization resulted in more variability between replicates at the surface than for the two deeper layer samples. Moreover, vertical trends were not reproducible between frozen and lyophilized sediments. It should be noted that the number of ASVs retrieved from both lyophilized and frozen sediments (a few hundreds per samples) is in line with what should be expected and supports the suitability of DADA2, compared to prior programs that inflated diversity 10 to 100 times (Edgar, 2013).

Finally, qPCR analysis did not detect any major or recurrent modification of DNA extraction yield after sediment lyophilization. This suggests that differences in alpha or beta diversity could rather be linked to either natural variability, or to variability introduced by amplification and/or sequencing.

Together, these data suggest that lyophilization of marine sediments does not seem to lead to large biases in microbial taxonomic diversity evaluation. However, caution should be taken, especially when interpreting small amplitude variations of alpha diversity.

Having established that frozen and freeze-dried sediments were both amenable for 16S rRNA gene sequencing analyses, we studied the effect of a historical contamination gradient recorded vertically in Toulon Bay. Using ${ }^{210} \mathrm{~Pb}$ dating, Tessier et al. (2011) showed that Toulon Bay experienced an important chemical contamination event during World War II, most probably associated with the scuttling of the French fleet. It resulted in a strong metal enrichment of the sediment, particularly for total mercury $(\mathrm{HgT})$ concentrations. As a consequence, $[\mathrm{HgT}]$ vertical profile has been a reliable dating tool for every new cores at this site, in addition to providing information on the contamination level of the samples. Our sediment sampling approach allowed us to compare prokaryotic taxonomic diversity in sediment settled before, during, or after this historical contamination event. In addition to the historical contamination gradient, sediment underwent diagenesis. Sediment diagenesis can lead to the development of a very reductive environment. According to a previous temporal survey performed at the same 
272 sampling site in Toulon Bay, sediment layers deposited before and during the historical

273 contamination event are both anoxic and dominated by sulfate reduction. Closer to the surface,

274 the sediment layer deposited after the contamination event corresponds to either oxic or suboxic

275 conditions and is typically dominated by iron and manganese reduction due to its interaction with

276 the oxic water column (Dang et al., 2015). These varying and contrasted geochemical conditions

277 offered ideal conditions to evaluate how prokaryotic community structure changed over time and 278 responded to chemical multicontamination. Indeed, both diagenesis and the varying toxicity of 279 metal burden, this latter possibly attenuated by the presence of sulfides (Dang et al., 2015) and 280 modulated by long term adaptation to metal stress (> 70 years; Misson et al., 2016), could 281 contribute to structuring the community.

282 We observed an important community structure shift between the top sediment layer on 283 the one hand, and both intermediate and deep sediment layers on the other. We suspect that the 284 strong diagenetic redox gradient induced by the very first stages of the early diagenesis (i.e. 285 microbial mineralization of organic matter) is a very strong driver of prokaryotic community 286 structure in the sediments of Toulon Bay as already demonstrated in various freshwater and 287 marine sediments (e.g. Cornall et al., 2013; Ruuskanen et al., 2018; Jiménez et al., 2018). 288 Subsequently, the distance analysis showed very slight discrimination of samples originating 289 from before or contemporary to the historical contamination peak. These results suggest that the 290 strong and multiple historical contamination of Toulon bay likely affected the prokaryotic 291 benthic community, but far less than sediment aging and especially diagenesis-related redox 292 gradients.

293

294

295

296

297

298

299

300

301

302

303

304

305

\section{Acknowledgements}

We are grateful to the LASEM Toulon and French Navy divers for their help in sediment sampling, and to Philip Pelletier and Emmanuel Yumvihoze for their help with the analytical work. This work was performed in collaboration with the GeT core facility, Toulouse, France (http://get.genotoul.fr). We are indebted to the late Dr Cedric Garnier, from whom we learned so much, and who thoroughly documented the sediment contamination of Toulon Bay, and made this study possible.

\section{References}

Bey BS, Fichot EB, Dayama G, Decho AW, Norman RS. 2010. Extraction of high molecular weight DNA from microbial mats. BioTechniques 49:631-640. DOI: 10.2144/000113486. 
306

307

308

309

310

311

312

313

314

315

316

317

318

319

320

321

322

323

324

325

326

327

328

329

330

331

332

333

334

335

336

337

338

339

340

341

342

343

344

345

Brazeau ML, Blais JM, Paterson AM, Keller W, Poulain AJ. 2013. Evidence for microbially mediated production of elemental mercury $(\mathrm{Hg}-0)$ in subarctic lake sediments. Applied Geochemistry 37:142-148. DOI: 10.1016/j.apgeochem.2013.07.020.

Callahan BJ, Mcmurdie PJ, Rosen MJ, Han AW, Johnson AJA, Holmes SP. 2016. DADA2 : High-resolution sample inference from Illumina amplicon data. Nature Methods 13:581. DOI: 10.1038/nmeth.3869.

Cornall AM, Beyer S, Rose A, Streten-Joyce C, McGuinness K, Parry D, Gibb K. 2013. HClExtractable Metal Profiles Correlate with Bacterial Population Shifts in Metal-Impacted Anoxic Coastal Sediment from the Wet/Dry Tropics. Geomicrobiology Journal 30:48-60. DOI: 10.1080/01490451.2011.653083.

Dang DH, Lenoble V, Durrieu G, Omanović D, Mullot J-U, Mounier S, Garnier C. 2015. Seasonal variations of coastal sedimentary trace metals cycling: insight on the effect of manganese and iron (oxy)hydroxides, sulphide and organic matter. Marine Pollution Bulletin 92:113-124. DOI: 10.1016/j.marpolbul.2014.12.048.

Edgar RC 2013. UPARSE: highly accurate OTU sequences from microbial amplicon reads, Nat. Meth. 10, 996-998

Gianaroli L, Magli MC, Stanghellini I, Crippa A, Crivello AM, Pescatori ES, Ferraretti AP. 2012. DNA integrity is maintained after freeze-drying of human spermatozoa. Fertility and Sterility 97:1067-1073.e1. DOI: 10.1016/j.fertnstert.2012.02.014.

Jiménez MFS-S, Cerqueda-García D, Montero-Muñoz JL, Aguirre-Macedo ML, GarcíaMaldonado JQ. 2018. Assessment of the bacterial community structure in shallow and deep sediments of the Perdido Fold Belt region in the Gulf of Mexico. PeerJ 6:e5583. DOI: 10.7717/peerj.5583.

Kreader CA. 1996. Relief of amplification inhibition in PCR with bovine serum albumin or T4 gene 32 protein. Applied and Environmental Microbiology 62:1102-1106.

McMurdie PJ, Holmes S. 2013. phyloseq: An R Package for Reproducible Interactive Analysis and Graphics of Microbiome Census Data. PLoS ONE 8(4):e61217 Miller DN, Bryant JE, Madsen EL, Ghiorse WC. 1999. Evaluation and Optimization of DNA Extraction and Purification Procedures for Soil and Sediment Samples. Appl. Environ. Microbiol. 65:4715-4724.

Misson B, Garnier C, Lauga B, Dang DH, Ghiglione J-F, Mullot J-U, Duran R, Pringault O. 2016. Chemical multi-contamination drives benthic prokaryotic diversity in the anthropized Toulon Bay. Science of The Total Environment 556:319-329. DOI:

10.1016/j.scitotenv.2016.02.038.

Oksanen JF, Blanchet G., Friendly M., Kindt R., Legendre P., McGlinn D., Minchin PR, O'Hara RB, Simpson GL, Solymos P., Stevens MHH, Szoecs E, Wagner H. 2019. vegan: Community Ecology Package. R package version 2.5-6

Outridge PM, Sanei H, Courtney Mustaphi CJ, Gajewski K. 2017. Holocene climate change influences on trace metal and organic matter geochemistry in the sediments of an Arctic lake over 7,000 years. Applied Geochemistry 78:35-48. DOI: 10.1016/j.apgeochem.2016.11.018.

Peer] reviewing PDF | (2020:04:47389:1:1:NEW 26 Jan 2021) 
346 Parada AE, Needham DM, Fuhrman JA. 2016. Every base matters: assessing small subunit 347 rRNA primers for marine microbiomes with mock communities, time series and global field 348 samples. Environmental microbiology 18:1403-1414.

349 Pougnet F, Schäfer J, Dutruch L, Garnier C, Tessier E, Dang DH, Lanceleur L, Mullot J-U,

350

351

352

353

354

355

356

357

358

359

360

361

362

363

364

365

366

367

368

369

370

371

372

373

374

375

376

377

378

379

380 Lenoble V, Blanc G. 2014. Sources and historical record of tin and butyl-tin species in a Mediterranean bay (Toulon Bay, France). Environmental Science and Pollution Research International 21:6640-6651. DOI: 10.1007/s11356-014-2576-6.

Poulain, A.J., Aris-Brosou, S., Blais, J.M., Brazeau, M., Wendel (Bill) Keller, Paterson, A. 2015. Microbial DNA records historical delivery of anthropogenic mercury. The ISME Journal 9:2541-2550.

Pruesse E, Quast C, Knittel K, Fuchs BM, Ludwig W, Peplies J, Glöckner FO. 2007. SILVA: A comprehensive online resource for quality checked and aligned ribosomal RNA sequence data compatible with ARB. Nucleic Acids Research 35:7188-7196. DOI: 10.1093/nar/gkm864.

Quast C, Pruesse E, Yilmaz P, Gerken J, Schweer T, Yarza P, Peplies J, Glöckner FO. 2013. The SILVA ribosomal RNA gene database project: Improved data processing and web-based tools. Nucleic Acids Research 41:590-596. DOI: 10.1093/nar/gks1219.

R Core Team. 2017.R: A Language and Environment for Statistical Computing. Vienna: R Foundation for Statistical Computing.

Ruuskanen MO, St. Pierre KA, St. Louis VL, Aris-Brosou S, Poulain AJ. 2018. Physicochemical Drivers of Microbial Community Structure in Sediments of Lake Hazen, Nunavut, Canada. Frontiers in Microbiology 9. DOI: 10.3389/fmicb.2018.01138.

Stein LY, Duc MTL, Grundl TJ, Nealson KH. 2001. Bacterial and archaeal populations associated with freshwater ferromanganous micronodules and sediments. Environmental Microbiology 3:10-18. DOI: 10.1046/j.1462-2920.2001.00154.x.

Tessier E, Garnier C, Mullot J-U, Lenoble V, Arnaud M, Raynaud M, Mounier S. 2011. Study of the spatial and historical distribution of sediment inorganic contamination in the Toulon bay (France). Marine Pollution Bulletin 62:2075-2086. DOI: 10.1016/j.marpolbul.2011.07.022.

Wafo E, Abou L, Nicolay A, Boissery P, Perez T, Ngono Abondo R, Garnier C, Chacha M, Portugal H. 2016. A chronicle of the changes undergone by a maritime territory, the Bay of Toulon (Var Coast, France), and their consequences on PCB contamination. SpringerPlus 5:1230. DOI: 10.1186/s40064-016-2715-2.

Weißbecker C, Buscot F, Wubet T. 2017. Preservation of nucleic acids by freeze-drying for next generation sequencing analyses of soil microbial communities. Journal of Plant Ecology 10:81-90. DOI: 10.1093/jpe/rtw042.

PeerJ reviewing PDF | (2020:04:47389:1:1:NEW 26 Jan 2021) 
Figure 1

Vertical variations of total $\mathrm{Hg}$ content in the sediment core.

Closed circles represent the sediment slices used for DNA sequencing. 


\section{[THg] (mg/kg)}

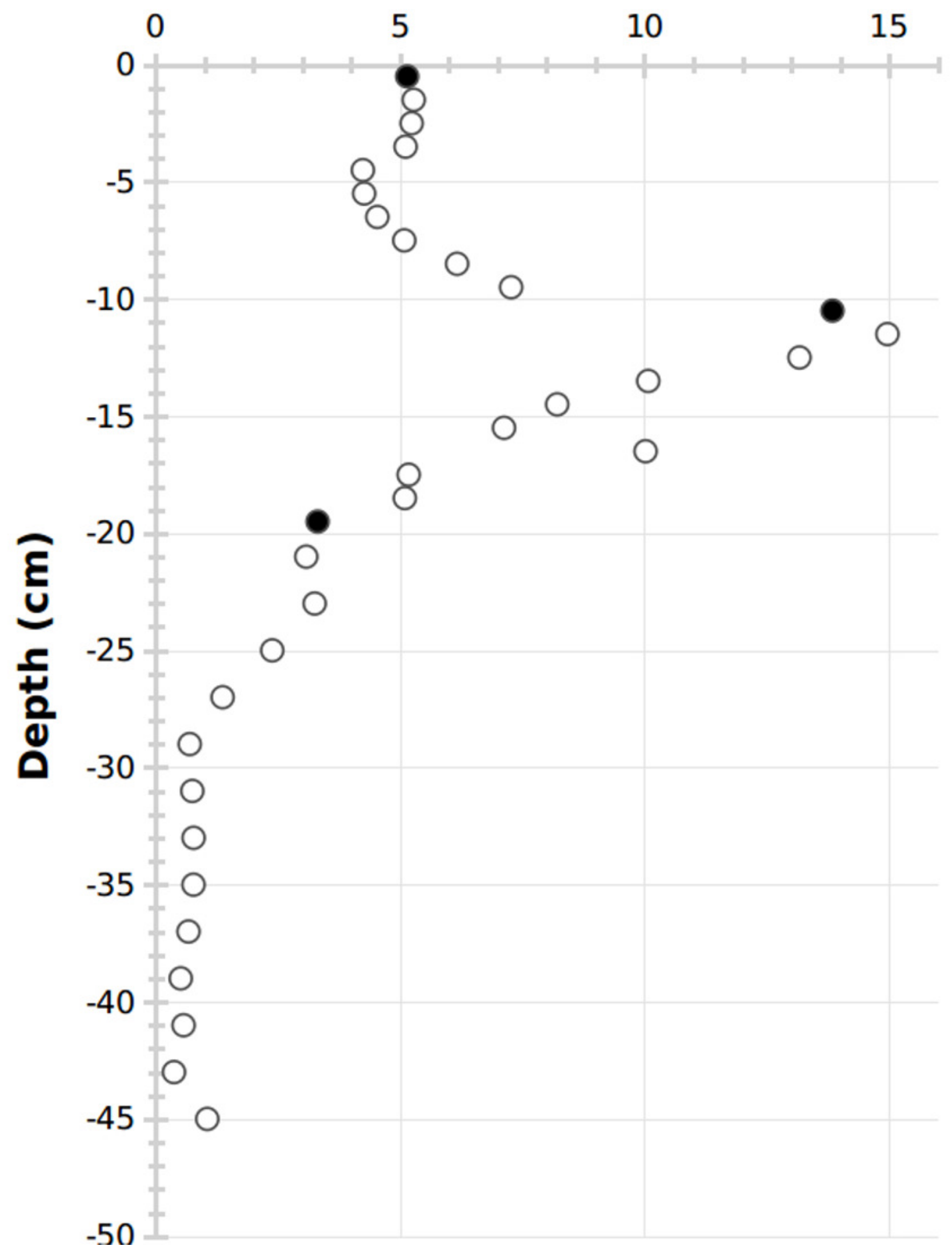


Figure 2

Bacterial 16S rRNA gene abundance.

"lyo" refers to lyophilized sediments, "fro" refers to frozen sediments.

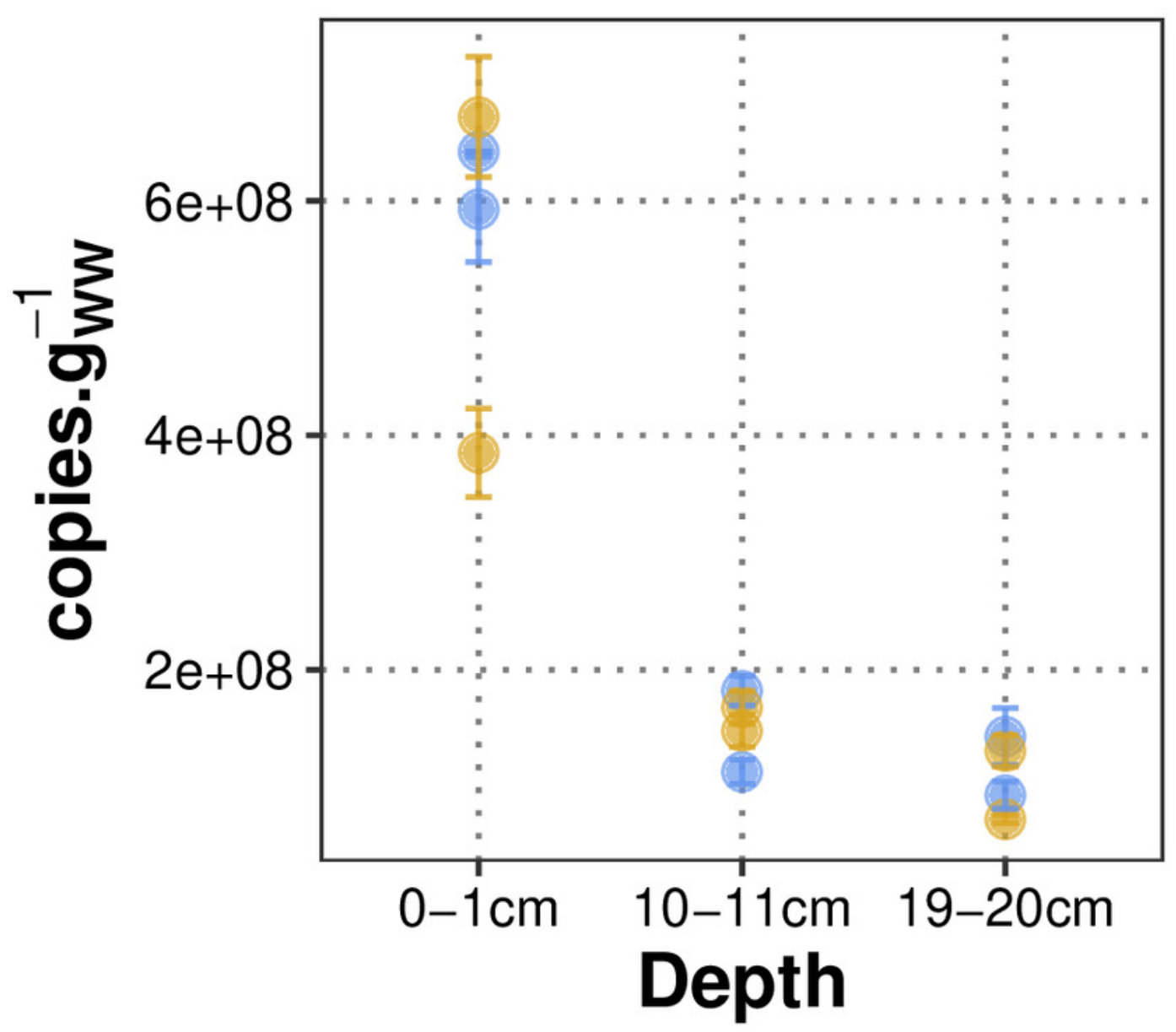


Figure 3

Comparison of rarefaction curves according to sediment treatment and depth.

"Iyo" refers to lyophilized sediments, "fro" refers to frozen sediments.
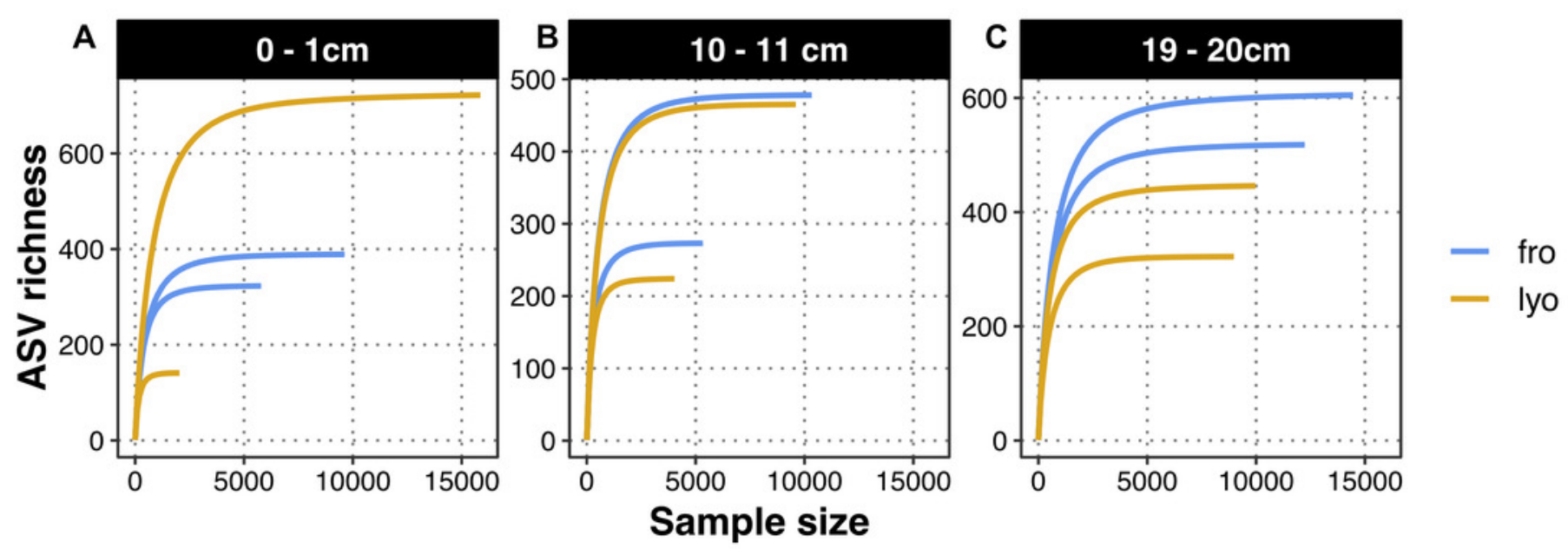
Figure 4

Alpha diversity metrics as a function of sediment treatment and depth.

"lyo" refers to lyophilized sediments, "fro" refers to frozen sediments.
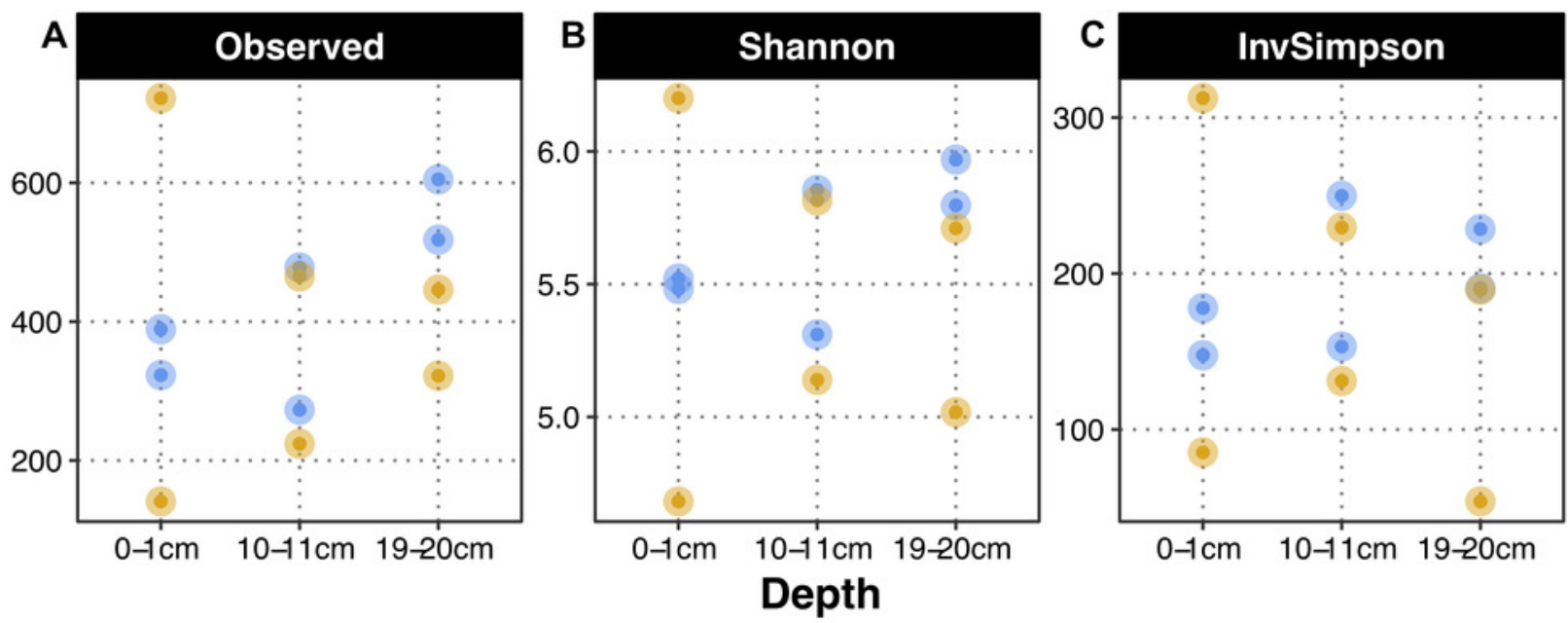

- fro

- lyo 


\section{Figure 5}

Community structure with phylum or class contribution according to sediment treatment and depth.

Duplicates were not grouped in order to allow the evaluation of the reproducibility of the analysis. Phyla or classes never representing more than $1 \%$ in any sample are grouped as "Other" for their corresponding domain or phylum. On the x-axis, "lyo" refers to lyophilized samples, "fro" refers to frozen samples. 

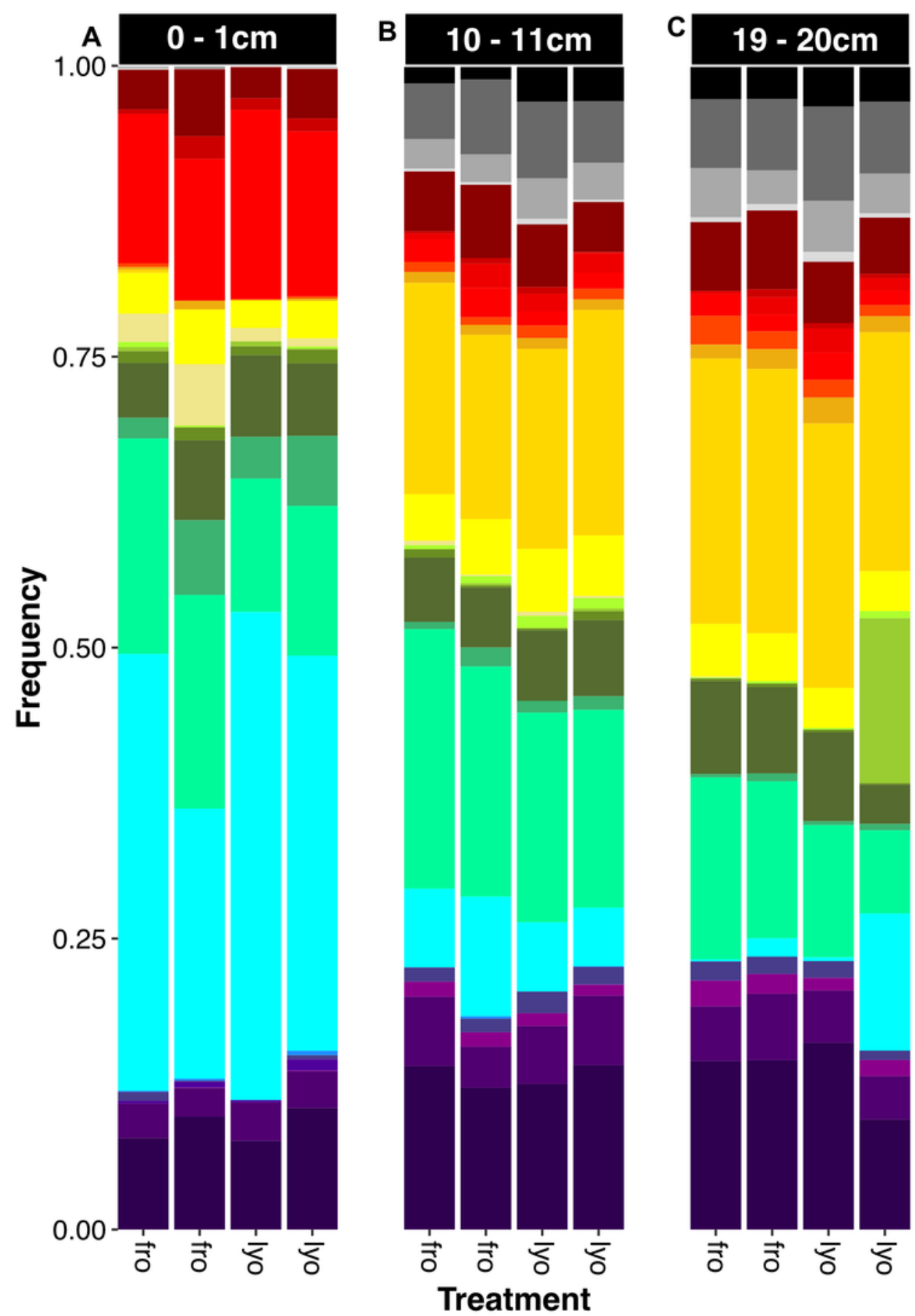

\section{Microbial taxa}

Asgardaeota

Crenarchaeota

Euryarchaeota

Other.Archaea

Acidobacteria

Actinobacteria

Atribacteria

Bacteroidetes

Calditrichaeota

Anaerolineae

Dehalococcoidia

Other.Chloroflexi

Cyanobacteria

Campylobacterota

Firmicutes

Gemmatimonadetes

Planctomycetes

Alphaproteobacteria

Deltaproteobacteria

Gammaproteobacteria

Proteobacteria_Unknown

Spirochaetes

Verrucomicrobia

Zixibacteria

Other.Bacteria

Unknown 
Figure 6

PCoA representation of weighted UniFrac distance between samples according to sediment treatment or depth.

"lyo" refers to lyophilized sediments, "fro" refers to frozen sediments.
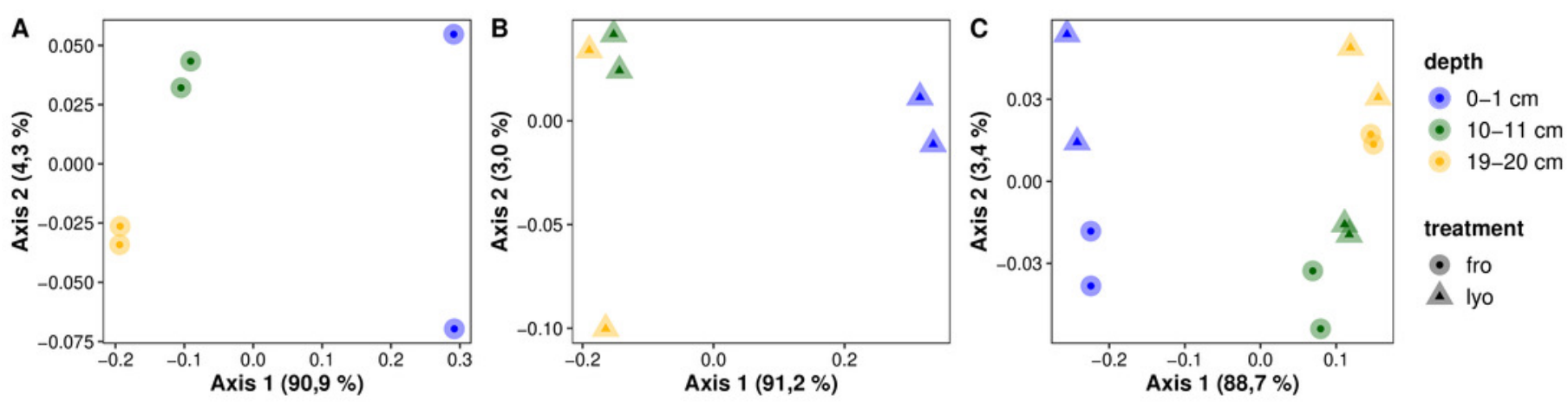